SCIENTIFIC LETTER

\title{
Echocardiographic risk factors predisposing to sudden cardiac death in hypertrophic cardiomyopathy
}

\author{
P P Dimitrow, J S Dubiel
}

Heart 2005;91:93-94. doi: 10.1136/hrt.2003.030353

1 n patients with hypertrophic cardiomyopathy (HCM), the low positive predictive accuracy of the previously recognised risk factor for sudden death-that is, non-sustained ventricular tachycardia, syncope, abnormal blood pressure response to exercise, family history of sudden death, and massive left ventricular (LV) hypertrophy-is a major limitation. ${ }^{1-5}$ Patients with a combination of two or more sudden death risk factors have been recently identified as higher risk group. ${ }^{124}$ Extreme LV hypertrophy $>30 \mathrm{~mm}$ does not appear to be a single key determinant of sudden death. ${ }^{2}{ }^{4}$ In searching for other morphological substrates that culminate in the above mentioned sudden death risk factors, we hypothesised that a small LV cavity may appear as a predictor of sudden death because it is commonly associated with several risk factors for sudden death: syncope, 5 abnormal blood pressure response to exercise, and massive LV hypertrophy. ${ }^{3}$

To assess the cumulative effect of increased septal hypertrophy and decreased LV cavity size we used the proportion of two echocardiographic parameters measured at end diastole (the ratio of septal thickness to left ventricular diastolic diameter (S/LVDd)). The aim of the study was to compare sudden death rate between patients with S/LVDd index $>0.5$ and concomitantly reversed septal curvature (group 1) and remaining patients (group 2).

\section{METHODS}

We retrospectively analysed 168 patients with HCM $(\geqslant 20$ years) referred to our tertiary centre and followed up from 116 years (between 1986 and 2002). Seventeen patients were excluded from the analysis for the following reasons: development of LV cavity enlargement and septal thinning during follow up (evolution into dilated phase of HCM, six patients); non-cardiac death (one patient); septal alcohol ablation (seven patients); and maximum LV hypertrophy not located in the septum (three patients).

According to the septal contour assessed in the apical four chamber echocardiographic view patients were divided into two categories: with reversed septal curvature and with nonreversed curvature pattern as previously described. ${ }^{6}$

On the basis of initial echocardiograms the study patients were divided into two groups: group 1 comprised 43 patients with S/LVDd index $>0.5$ and concomitantly reversed septal curvature. All the remaining patients (108 patients) were classified as group 2. The septal contour was used as a prespecified criterion, whereas the separating value of the S/LVDd index was determined in post hoc analysis. All patients who died suddenly had an S/LVDd index $>0.5$.

The analysis of traditional sudden death risk factors included non-sustained ventricular tachycardia in Holter monitoring, syncope, family history of sudden death, and septal thickness $>30 \mathrm{~mm}$.

Data are expressed as mean (SD). Survival was analysed by Kaplan-Meier methods. Relative risk (RR) and 95\% confidence interval (CI) were calculated by the univariate and

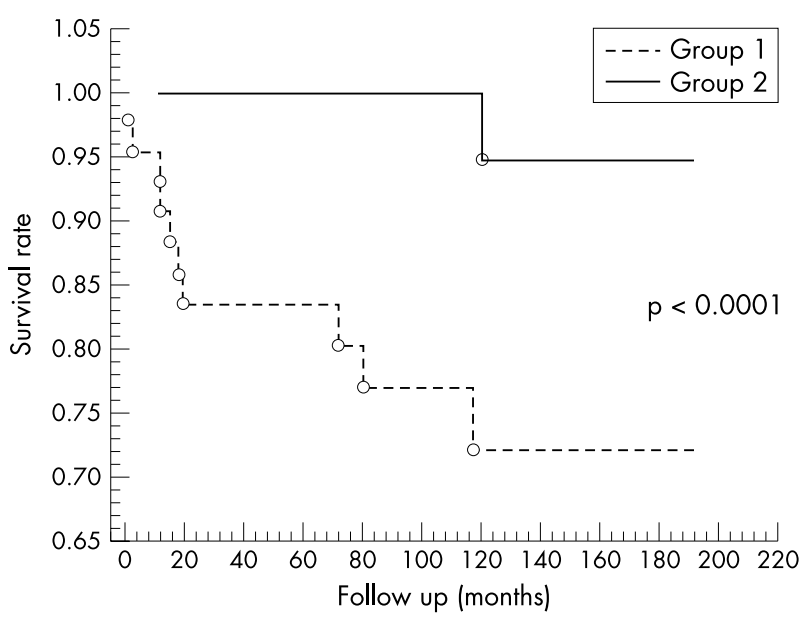

Figure 1 Comparison of sudden death-free survival rate between groups 1 and 2 .

multivariate Cox regression models. Differences were considered significant when $\mathrm{p}<0.05$. The confidence interval was at the $95 \%$ level.

\section{RESULTS}

One hundred and fifty one patients were followed up over a mean of 7 (4.3) years. There were 11 fatal events and within the first five years the sudden death-free survival rate was $95 \%$ in the overall cohort. The incidence of sudden death was $10.1 / 1000$ person/year and annual mortality was $1 \%$. Comparing group 1 with 2 , five year survival was $83 \% v$ $100 \%$ (fig 1); incidence of sudden death was $31.2 v 1.4 / 1000$ person/year; and mean annual mortality was $3.1 \% \vee 0.1 \%$ ( $\mathrm{p}<0.001$ for all differences).

The combined echocardiographic criteria (S/LVDd index $>0.5$ with reversed septal curvature) predicted sudden death with $91 \%$ sensitivity and $76 \%$ specificity. The positive and negative predictive accuracy was $23 \%$ and $97 \%$, respectively.

An age adjusted univariate and multivariate Cox regression model showed that reversed septal curvature solely (univariate RR 20.2, 95\% CI 2.56 to $159, \mathrm{p}<0.004$; multivariate RR $11.8,95 \%$ CI 1.15 to $121, \mathrm{p}<0.038$ ) or together with S/LVDd index $>0.5$ (univariate RR 33.2, 95\% CI 4.21 to 264 , $\mathrm{p}<0.001$; multivariate RR 36.8, 95\% CI 3.25 to 417 , $\mathrm{p}<0.004$ ) was a potent predictor of sudden death. Only in univariate analysis, significant septal hypertrophy was a predictor of sudden death but only if the cut off value was lower than previously reported-that is, $25 \mathrm{~mm}$ ( RR 7.86,

Abbreviations: $\mathrm{HCM}$, hypertrophic cardiomyopathy; LV, left ventricular; RR, relative risk; S/LVDd, ratio of septal thickness to left ventricular diastolic diameter 
95\% CI 2.04 to $30.3, \mathrm{p}<0.003$ ) instead of $30 \mathrm{~mm}$ (RR 0.87, $95 \%$ CI 0.10 to $7.13, \mathrm{p}=0.89)$.

\section{DISCUSSION}

Small LV cavity was related to syncope ${ }^{5}$ and abnormal blood pressure response to exercise. The small LV cavity may facilitate exercise induced hypotension through activation of LV mechanoreceptors. An exaggerated activation of LV mechanoreceptors may induce a withdrawal of sympathetic tone to the peripheral resistance vessels, resulting in sudden hypotension and haemodynamic collapse. A small LV cavity may predispose to hypotensive syncope during LV low inputlow output failure triggered by tachycardia. ${ }^{5}$ It has been suggested that the combination of low filling volume and non-sustained ventricular tachycardia can be particularly detrimental, leading to sudden depression of cardiac output with profound hypotension. ${ }^{5}$ In these circumstances ventricular fibrillation may develop as the summative effect of myocardial ischaemia (due to hypotension mediated decrease of coronary perfusion pressure) and electrical instability (non-sustained ventricular tachycardia). Also, supraventricular tachycardia predisposes to hypotensive syncope in the presence of a small LV cavity due to the development of similar low input-low output failure.

In a pathomorphological study ${ }^{7}$ advanced abnormality in myocardial architecture (corresponding to reversed septal curvature) was common in patients who died at a mean age of 25 years. In contrast, most patients who were older than 65 years when they died had a normal circular unit surrounding the LV cavity as a morphological marker of non-reversed septal configuration.

In conclusion, the proposed combination of echocardiographic parameters reflecting a significant morphological imbalance between hypertrophied septum with reversed curvature and narrowed LV cavity allows retrospective identification of a subgroup of patients with HCM who have an increased risk of sudden death. These preliminary results need to be confirmed by prospective analyses.

\section{Authors' affiliations}

P P Dimitrow, J S Dubiel, 2nd Department of Cardiology, Jagiellonian University School of Medicine, Krakow, Poland

Correspondence to: Dr Pawel P Dimitrow, 2nd Department of Cardiology CMUJ, ul. Kopernika 17, 31-501 Krakow, Poland; dimitrow@mp.pl

Accepted 2 April 2004

\section{REFERENCES}

1 Elliott PM, Poloniecki J, Dickie S, et al. Sudden death in hypertrophic cardiomyopathy: identification of high risk patients. J Am Coll Cardiol 2000;36:2212-8

2 McKenna WJ, Behr R. Hypertrophic cardiomyopathy: management, risk stratification and prevention of sudden death. Heart 2002;87:169-76.

3 Spirito P, Bellone P, Harris K, et al. Magnitude of left ventricular hypertrophy and risk of sudden death in hypertrophic cardiomyopathy. N Engl J Med 2000;342:1778-85

4 Elliott P, Blanes JR, Mahon N, et al. Relation between severity of left-ventricular hypertrophy and prognosis in patients with hypertrophic cardiomyopathy. Lancet 2001;357:420-4.

5 Nienaber CA, Hiller S, Spielmann RP, et al. Syncope in hypertrophic cardiomyopathy: multivariate analysis of prognostic determinants. J Am Coll Cardiol 1990; 15:948-55.

6 Lever HM, Karam RF, Currie PJ, et al. Hypertrophic cardiomyopathy in the elderly: distinctions from the young based on the cardiac shape. Circulation 1989;79:580-9.
7 Kuribayashi T, Roberts WC. Myocardial disarray at junction of ventricular septum and left and right ventricular free walls in hypertrophic cardiomyopathy. Am J Cardiol 1992;70:1333-40.

\section{WEB TOP 10}

www.heartinl.com

These articles scored the most hits on Heart's website during October 2004

1 Should all patients with an acute myocardial infarction be referred for direct PTCA?

PP de Jaegere, PW Serruys, ML Simoons

November 2004;90:1352-7. (Education in Heart)

2 Biochemical markers of myocyte injury in heart failure Y Sato, T Kita, Y Takatsu, T Kimura

October 2004;90:1110-3. (Review)

3 Management of acute coronary syndromes: an update KAA Fox

June 2004;90:698-706. (Education in Heart)

4 Aldosterone blockade in cardiovascular disease $A D$ Struthers

October 2004;90:1229-34. (Education in Heart)

5 Warfarin for non-rheumatic atrial fibrillation: five year experience in a district general hospital

ZR Yousef, SC Tandy, V Tudor, F Jishi, RJ Trent, DK Watson, RPW Cowell

November 2004;90:1259-62. (Cardiovascular medicine)

6 Cardiovascular disease: different strategies for primary and secondary prevention?

FDR Hobbs

October 2004;90:1217-23. (Education in Heart)

7 Should patients with acute ST elevation MI be transferred for primary $\mathrm{PCl}$ ?

S D Kristensen, $H R$ Andersen, $L$ Thuesen, $L R$ Krusell, $H E$ Botker, J F Lassen, T T Nielsen

November 2004;90:1358-63. (Education in Heart)

8 How should we assess patent foramen ovale?

C Seiler

November 2004;90:1245-7. (Editorial)

9 Autonomic changes in patients with heart failure and in post-myocardial infarction patients

MP Frenneaux

November 2004;90:1248-55. (Review)

10 Joint British recommendations on prevention of coronary heart disease in clinical practice

December 1998;80:1-29.

Visit the Heart website for hyperlinks to these articles, by clicking on "Top 10 papers"

www.heartinl.com 